\title{
The Research on the Protection of Ethnic Characteristic Villages in Taiwan
}

\author{
Kun Wang ${ }^{1}$, Daishan Mo ${ }^{1}$ \\ ${ }^{1}$ College of Management, Yangtze Normal University.
}

\begin{abstract}
Taiwan boasts of small, scattered and numerous ethnic villages, which have, in the process of development, suffered from imbalance between the ecosystem conservation and ethnic village tourism development, the loss of traditional cultural resources, DE characterization of ethnic villages arising from assimilation, imperfection of policies and regulations regarding protection and development; thus, the characteristic minority villages in Taiwan should be protected and developed by balancing the relationship between the ecosystem conservation and ethnic village tourism development, developing and maintaining the characteristic traditional cultural resources, fully mining and carrying forward the characteristics of ethnic villages, and perfecting the policies and regulations regarding protection and development.
\end{abstract}

Keywords: Characteristic villages; Minorities; Protection; Ethnic culture; Taiwan.

\section{Introduction}

In recent years, the protection of characteristic minority villages has got more attention gradually, evidenced by the planning and guidelines developed by the State Ethnic Affairs Commission and the Ministry of Finance etc. In 2014, China identified its first batch of "Characteristic Minority Villages in China", totaling 340 villages. The so-called characteristic minority villages are natural or administrative villages characterized by relatively inhabited minority population and a high proportion, complete functions of production and living, and obvious minority cultural traits and settlement features. Characteristic minority villages have epitomized the socioeconomic development features and cultural characteristics of minorities in terms of the industrial structure, dwelling style, village styles and features, customs and manners, etc., typically reflecting the historical formation and evolution process of minority dwelling places in different periods, regions and cultural types. They have retained the cultural genes of minorities in a relatively intact way, condensed the historical crystallization of each minority culture, and embodied the diversity of Chinese civilization. Besides, they are effective carriers to inherit the ethnic culture, and the important resources for minorities and minority areas to speed up their development. Xiao T B, Shi H Y. (2007), Hong-qi amp W U (2009) and Chen H, Zhang P. (2012) separately studied and analyzed the characteristics of villages in minority areas as well as the operation characteristics. Mo D. (2012), Zhu F Y. (2012) and Li S. (2013) studied separately the protection, development and utilization methods of minority villages. ZHANG Xing. (2013) studied the major features of minority villages in Taiwan. Cheng M X, Chen X G and Huang Y X (2015) studied the important role of humanity factors in the protection of traditional ethnic villages. Zhang C (2015) studied systematically the important methods to protect and inherit the traditional villages. With the rapid expansion of modern civilization, ethnically traditional styles of characteristic minority villages have been damaged, the ecological environment is being destroyed, and the characteristics of age-old ethnic villages are disappearing at a high speed. Therefore, it seems necessary and urgent to proactively rescue and protect the characteristic minority villages, no matter for the purpose of developing the tourism in characteristic minority villages, facilitating the inheritance of ethnic culture and building a beautiful ecological environment, or for the sake of unity, stability and harmonious development in minority areas.

Taking the protection and development of ethnic characteristic villages in Taiwan as the object of study, this paper has analyzed systematically the status quo and problems of characteristic minority villages in Taiwan, and put forward specific measures to further protect and develop the characteristic minority villages. 


\section{Status Quo of Characteristic Minority Villages in Taiwan}

For historical reasons, these aboriginal villages are mainly distributed in central mountainous areas of Taiwan, and gathered into distinctive minority villages along the edge of alluvial plain, with a total number of around 588 minority villages. In general, the ethnic minorities in Taiwan present a geographical distribution: ethnic groups live scattered over vast areas while some live in individual concentrated communities in small areas. As a result, the minority villages are small, scattered and numerous. Ami residents are mainly distributed in 10 townships in Taitung City, Hualien County and Pingtung County. Atayal people are mainly distributed in 11 townships in Taipei County, Taoyuan County, Hsinchu County and other 5 counties in the northern half of Taiwan. In these numerous minority villages, some villages have something unique in geological conditions, natural resources or cultural accumulation, etc., and been within the scope of protection and development by Taiwan Provincial Government, and some villages have launched diversified forms of tourist activities including ecological leisure, cultural experience, exploration and knowledge-seeking, bringing a great opportunity for improvement of local residents' life. In 2001, Taiwan Provincial Government Council of Indigenous Peoples has entrusted the survey and assessment team made up of Professor Hong Jinxiong from National Chiayi University, Professor Shi Zhengren from Taiwan University and other 8 experts from a number of academic institutions to make an evaluation, the Swamui Village, Niahosa Village and Chashan Village in Alishan Township, Chiayi County, Baguali Tribe in Nanzhuang Township, Miaoli County, Jialan Village in Jinfeng Township, Taitung County and other five villages in five counties are selected as key tribes of indigenous peoples, striving to develop the tribes' industrial culture, ecological tourism and leisure tourism.

\section{Problems in the Protection of Characteristic Minority Villages in Taiwan}

\subsection{Imbalance between the Ecosystem Conservation And Ethnic Village Tourism Development}

The ecosystem conservation is aimed at the reconstruction of damaged ecosystem and the breeding and reproduction of endangered species. Specifically, it uses the principles of ecology to monitor the human interactions with ecosystem, harmonize the mutual relations of man and biosphere, and finally facilitate the protection and maintenance of sustainable utilization and maintenance of natural resources. Since modernization, the ecology of many aboriginal areas in Taiwan has been badly damaged, and the green hills and clear waters as well as the original ecological environment have been destroyed by various wastes and wastewaters, etc. arising from tourism. After the establishment of national parks, indigenous peoples have been involved in tourism, and the ecological environment has been protected to some extent. However, their living space is shrunk, thereby giving rise to several resistance conflicts between indigenous peoples and national parks. Such conflicts have ever occurred in Yushan National Park, Taroko National Park and Shei-pa National Park, etc. In the process of development, a crop of villages have, regardless of the actual conditions of villages, developed universally the tourism industry, to the extent that the traditional life order in the villages has been overwhelmed, and the villagers' attitude and positivity to community development have been hit hard. Yami Langdao Tribe in Lanyu Township, Taitung County and other villages have simply emphasized the primary conservation of cultural patterns and production and life styles in the protection, giving rise to the residents' low standards of living and the external migration of a great many villagers.

\subsection{Gradual Loss of Characteristic Traditional Cultural Resources in Ethnic Villages}

Ethnic culture is the nature of national development, and to protect the unique local culture of ethnic villages is to keep the source of living water of ethnic culture. Subject to different historical backgrounds of development, dwelling environments, production practices, religious beliefs, etc., all ethnic minorities have formed their own distinctive ethnic features, manifested in such characteristic customs as diet, costume, dwelling, etiquette, festival, daily life, weddings and funerals, etc. In recent years, during the mining and utilization of traditional minority culture, the ethnic cultures and national 
customs of characteristic villages have, to varying degrees, been gradually losing, including diversified forms of building houses, song and dance costumes, eating customs, etc. with national features. For instance, the Talatuas in Hualien Area had interrupted since Japanese Occupation, and only arisen once in 1978 after retrocession; the weaving of "Coke Tribe" is hit by modern civilization; likewise, the rattan plaited articles with Truku representative culture are only fabricated and used by very few people, owing to their out of use and low yield.

\subsection{Decharacterized Culture of Ethnic Villages Arising from Assimilation}

Traditional ethnic culture is the unique and priceless gems of wisdom created by all minorities in the long development process. Yet in the continuous development of modern civilization and technology, the prominent features inherent in the ethnic culture have been gradually assimilated, losing their original features. Nowadays, many indigenous peoples know their minority identity only, but have forgotten the languages, songs and traditions of their own ethnic minorities. What a pity! After all, it goes against the inheritance and diversity of ethnic culture. What's more, regardless of exquisite building and packaging, the cultural display activities launched by indigenous peoples in national parks are essentially selling the aboriginal culture (as commodities) in the tourist market, so that indigenous peoples generally think that they have lost their cultural dignity.

\subsection{Imperfect Policies and Regulations Regarding the Protection and Development of Ethnic Characteristic Villages}

Historically, rulers had ever practiced different policies to indigenous peoples and their villages in Taiwan. The period of Japanese Occupation witnessed the conquest by brute force and migration. The Japanese rulers issued the Official Wildland Enforcement Rules, adopted the policy of enslavement, and launched the "Kominka Movement", trying to assimilate indigenous peoples into Japanese people. In such an era and policy context, minority villages had been tremendously damaged, impossible to seek any protection and development. At the beginning of Taiwan's Retrocession, under the guidance of big-nationality chauvinism, the Kuomintang government has, in the early of the reign, also been inclined to the policy of assimilation to indigenous peoples. The 1980s saw the gradual rise of national movement among indigenous peoples in Taiwan. Advocated, organized and driven by educated youth of indigenous peoples, ethnic minorities in Taiwan have launched campaigns to strive for living space and cultural power in nearly 40 years, so that local governments at all levels in Taiwan have been forced to issue hundreds of laws and regulations for guaranteeing all rights of indigenous peoples. The statistics of "Taiwan Indigenous Peoples Resource Center" show that since April 1997, local governments at all levels have issued 376 regulations concerning the indigenous peoples, involving their land, education, identity, culture and political status, etc. However, these policies and regulations are not sound in terms of the village protection and development for indigenous peoples, unable to carry out all-round and targeted protection and development to their villages.

\section{Measures to Protect the Characteristic Minority Villages in Taiwan}

There are a lot of specific practices in protection and development of characteristic villages in Taiwan. Based upon the investigation and analysis on the recent efforts in the village protection and development within a dozen of typical characteristic minority villages, including "Smangus Tribe" in Jianshi Township, Hsinchu County, Tanayiku Tsou Swamui Village in Alishan Township, Chiayi County, and Taroko "Coke Tribe" of Fushi Village in Sioulin Township, Hualien County, the author has summed up major measures to protect and construct the characteristic minority villages as follows:

\subsection{To Balance the Relationship between the Ecosystem Conservation and Ethnic Village Tourism Development}

Minority villages have their own living and development space, and their contents, forms, connotations and means, etc. of protection and development should vary with the changes in economic, social and cultural environment. During the protection and development, the rapport of 
immediate interests and long-term interests should be handled well, avoiding any severe damage to the ecology. For instance, Lunpi Tribe in Datung Township, Yilan County and other characteristic villages have, relying on their own resources, seized a series of opportunities including ecosystem conservation, ecological breeding, cultural development and rural tourism construction implemented by the government, to adjust the economic patterns and institutional norms, truly achieving the goals of sustainable inheritance between characteristic tourism in villages and ecosystem conservation, steady economic and social development and happy life of villagers.

\subsection{To Develop and Maintain the Characteristic Traditional Cultural Resources}

The important festivals and customs for minorities in ethnic characteristic villages can not only disseminate and inherit effectively the ethnic culture, but also meet the people's spiritual and cultural needs, and facilitate the mutual respect and understanding of ethnic minorities. For instance, Taitung Sugar Refinery's "East Taiwan Ata Culture" is devoted to the unique Paiwan colored glaze culture, so that tourists may appreciate and experience the azure stone handicraft and creative tribe goods. For another example, the Taroko cultural life experience camp may enable the tourists to have first-hand experience of Taroko facial tattoo, operate the common traditional handicraft of indigenous peoples in Taiwan, and utilize simple tools and hemp yarns to weave beautiful cotton piece goods. The locally available Moso bamboo or Makino bamboo, etc. may be used to make the bamboo rice, which is the staple food of indigenous peoples in Taiwan. Again such, in the Mazu culture, Harvest Festival, Dong-Gang Ying-Wang Peace Ritual and other festivals of widespread belief among folks in Taiwan, the public will sing and dance joyously in the street, and pray for peace and blessing, in the hope of harvest celebration again next year. Further, they will invite warmly the spectators to dance together, feeling the atmosphere of festival. Indigenous peoples, tribes and villages in Taiwan are very mysterious to many tourists, and village tourism programs may be developed to attract tourists, which will not only protect and inherit the minority culture, but also boost the blending of ethnic multiculture.

\subsection{To Fully Mine and Carry Forward Tthe Characteristics of Ethnic Villages}

During the protection and construction of characteristic minority villages, all means should be tried to mine and generalize the traditional culture of ethnic minorities for the purpose of protection, development and utilization, and various forms of protection should be employed to further mine and protect the ethnic culture. First, with further survey to folk cultural heritage scattered throughout the region, different cultural characteristics are mined by means of collection, collation translation, publishing and research, etc., followed by classified filing and safekeeping; in particular, all kinds of items are preserved by setting up the culture rooms or memorial halls, to display the traditional instruments of labor, articles of daily use, costumes, musical instruments and handicrafts, etc. and preserve the distinctive national memories. In conjunction with folklore performances, villagers are encouraged and guided to show the traditional folkway lively by integrating organically the traditional songs \& dances, languages, festival celebrations, life customs and traditional handicraft into daily life, and carry on the vivid memory of the nation, so as to do well in static protection and dynamic inheritance of ethnic culture. For example, Taroko "Coke Tribe" takes the advantage of neighboring national parks to show, train and promote their ethnic culture, which has not only reproduced the endangered culture and preserved the connotation of traditional culture, but also added new traits in accord with the characteristics of times, and finally enhanced the identity awareness of ethnic members, which is very representative.

\subsection{To Perfect the Policies and Regulations Regarding Protection and Development of Characteristic Minority Villages}

To perfect the policies and regulations on protection and development of characteristic minority villages is an institutional guarantee to protect and develop the characteristic villages, including the management mechanism made up of: a power decision-making body based on equality and democracy, a regulatory authority based on efficiency and unified harmonization, and an executing 
agency based on fairness and efficiency; the supervisory mechanism based on representativeness, separation of powers, effectiveness and timeliness; the public communication mechanism based on humanization and popularization; the public mobilization mechanism based on benefit and respect, etc. When developing the tourism based on the "ecosystem conservation", Tanayiku Tsou Swamui Village and "Smangus Tribe" have, by establishing an active and effective management system and a strict regulatory system, and executing them in the operation, built good behavior orders to the protection and development of stockaded villages. Thus, greater efforts should be devoted to issue more policies and regulations conducive to protection and development of characteristic minority villages, such as rules on infrastructure repair in villages and protection of traditional national culture, for the purpose of restoration to characteristic villages inhabited by indigenous peoples, protection to intangible cultural heritage in villages and boosting the development of characteristic ethnic culture.

\section{Acknowledgements}

The authors thanks the support of the National Civil Affairs Commission Projects, they are the Study on the Harmonious Development of Multi-ethnic Culture in Wuling Mountain Area (Grant No: 2015-GM-133), and the Ethnic Minority Village Protection and Development Experience in China (Grant No: MSY10011).

\section{References}

[1]. Xiao T B, Shi H Y. Operation of Village Self-governance and Regional Characteristics in China-An Analysis Based on Data from A National Sampling Survey[J]. Journal of Huazhong Normal University, 2007.

[2]. Hong-qi amp W U, Hu L W. The Image Characteristics of the Ancient Liangxi Village and the Protection of Its Landscape[J]. Journal of Wuyi University, 2009.

[3]. Chen H, Zhang P. Analysis on the Protection Measures of Special Culture of the Construction of Ethnic Minorities Villages:Illustrate the Protection Plan of Special Ethnic Minorities of Gansu Province Zhangjiachuan Hui Autonomous County Zhangjiachuan Town Chawan Village[J]. Value Engineering, 2012.

[4]. Mo D. Utilization of Traditional Ecology Knowledge in Ethnic Minority Villages Reservation and Development_— with a special reference to the Zou Ethnic in Shanmei Village,Taiwan[J]. Guangxi Ethnic Studys, 2012.

[5]. Zhu F Y. Characteristics and Protection of Ethnic Cultural Villages of Qiandongnan[J]. Journal of Kaili University, 2012.

[6]. Li S. The Protection and Utilization of the Ancient Village in the Forest Park—-Taking the E Zhuang Ancient Village National Forest Park for Example[J]. China Forest Products Industry, 2013.

[7]. ZHANG Xing. On the role of Taiwan village's mediator[J]. Journal of Hebei University of Engineering, 2013.

[8]. Cheng M X, Chen X G, Huang Y X. Characteristics and protection approaches of human settlement in ancient villages of Jiangxi: a case study of ancient Dongyuan Zengs' Village.[J]. Journal of Landscape Research, 2015(3).

[9]. Zhang C. Study on Value Characteristics of Traditional Village and Its Protection Strategy[C]// International Conference on Economics, Social Science, Arts, Education and Management Engineering. 2015. 